\title{
Microwave-Assisted Silver-Catalyzed Protodecarboxylation and Decarboxylative Iodination of Aromatic Carboxylic Acids
}

\author{
Kun Zhan and Yi Li * \\ Department of Chemistry, Xi'an Jiaotong-Liverpool University, Suzhou 215123, China; kun.zhan@xjtlu.edu.cn \\ * Correspondence: yi.li@xjtlu.edu.cn; Tel.: +86-0512-88161431
}

Received: 10 October 2017; Accepted: 24 October 2017; Published: 26 October 2017

\begin{abstract}
Carboxylic acids and their derivatives are readily available from both natural and synthetic sources. Apart from being used as direct substrates in the functional transformation, aryl carboxylic acids have found more applications in aromatic functionalization, especially in decarboxylation coupling reactions. Microwave-assisted protodecarboxylation and decarboxylative iodination of aromatic carboxylic acids were achieved with excellent yields in the presence of $\mathrm{Ag}_{2} \mathrm{CO}_{3}$ catalyst and $\mathrm{K}_{2} \mathrm{~S}_{2} \mathrm{O}_{8}$. These reactions will be helpful for better understanding of decarboxylation-related coupling reactions and also have the potential of being used as a practical labeling method to synthesize regioselective deuterium and iodine-labelled compounds for chemical, biological, and medicinal research.
\end{abstract}

Keywords: microwave-assisted organic synthesis; protodecarboxylation; decarboxylation; iodination; carboxylic acids; deuterium-labelled compounds; iodine-labelled compounds

\section{Introduction}

Carboxylic acids and their derivatives are common chemicals of relatively low price with diverse structures, readily available from both natural and synthetic sources. They have long functioned as valuable intermediates and precursors in the construction of carbon frameworks [1-3].

The decarboxylative cross-coupling reaction is one of the most powerful strategies developed over the decades to form a carbon-carbon bond or carbon-heteroatom bond and is advantageous over traditional cross-coupling or addition reactions, which generally require the use of preformed organometallic reagents [4-6]. Transition metals are essential for decarboxylation and coupling reaction, the two main steps in this process. Decarboxylative cross-coupling reaction starts with the formation of metal carboxylates from carboxylic acid substrate and metal catalyst, the pivotal step of $\mathrm{CO}_{2}$ extrusion from the metal salts of carboxylates typically proceeds under rather forcing reaction conditions. Over the years, various metal catalytic systems - both monometallic and bimetallic-have been discovered and developed to turn this strategy applicable for organic synthesis [4,7].

Protodecarboxylation reaction is of high preparative utility in this field, first as a precursor step of decarboxylative cross-coupling reaction and also as a constructive model method for further functionalization design [8-10]. The traditional copper-catalyzed decarboxylation is hampered by the extremely high temperature and costly ligands [11]. The recent research have found that silver in metallic catalyst systems can effectively promote this reaction (Scheme 1) [12-14]. However, these decarboxylative transformation reactions either require $20 \mathrm{~h}$ or an even longer time to obtain satisfied reaction yields under conventional heating conditions (Scheme 1a,b) or is only applicable for some specific substituted benzoic acids and heteroaromatic benzoic acids (Scheme 1c). Development of an effective and facile protodecarboxylation reaction is still highly desirable for useful organic transformations and their applications in the decarboxylative cross-coupling reaction. 
(a)<smiles>O=C(O)c1ccccc1</smiles>

(b)<smiles>O=C(O)c1cc[R]cc1</smiles>

(c)<smiles>[R]c1ccccc1C(=O)O</smiles>
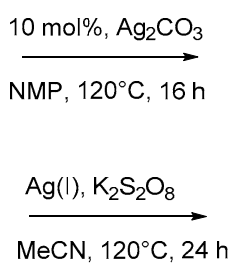

$10 \mathrm{~mol} \%, \mathrm{Ag}_{2} \mathrm{CO}_{3}$

DMSO, $120^{\circ} \mathrm{C}, 16 \mathrm{~h}$

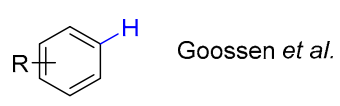<smiles>[R17]1ccccc1</smiles>

Greaney et al.<smiles>[R]c1ccccc1</smiles>

Larrosa et al

Scheme 1. Silver-catalyzed protodecarboxylation reactions.

One of the interesting, synthetically valuable functionalizations from the controlled protodecarboxylation of carboxylic acids is halogenation on the aromatic ring where the carboxylate groups are removed. Aryl iodides have played essential roles in organic synthesis as substrates for many organic reactions, and also found increasing applications in medical research and drug discovery [15-17]. Specifically, radioactive organic iodides has been widely used in nuclear medicine and radiotherapy science, such as hypothyroidism treatment, single-electron-emission computed tomography, and preclinical X-ray imaging [18-20]. Several radioactive iodine isotopes, for example, ${ }^{125} \mathrm{I},{ }^{131} \mathrm{I}$, and ${ }^{123} \mathrm{I}$, act successfully as labeling agents in the pharmacokinetic studies [21]. However, aryl and heteroaryl iodides are much more difficult to acquire compared to their corresponding bromides and chlorides, and the facile iodination of aromatic compounds with high yield and broad substrate scope are still out of reach in organic chemistry $[17,22,23]$.

Great efforts have been devoted and several useful strategies were developed to synthesize functionalized aromatic, hetero-aromatic iodides, but mainly based on Finkelstein reaction [24-26], the traditional aromatic halogen exchange reaction. The practical application of this approach has been limited by its high reaction temperature, polar solvents, costly ligands, and long reaction time, using aromatic halides as starting materials, which itself needs multistep synthesis, even if it is achievable under a mild reaction conditions, such as photo-induced metal-catalyst-free aromatic halogen exchange reaction, as discovered by Li (Scheme 2) [27]. As aromatic carboxylic acids are more widely available and cheaper, the successful decarboxylative iodination reaction will provide a reliable route for aryl iodides and has the potential of general application in organic synthesis. Very recently, an interesting transition metal-free decarboxylative iodination was reported by Larrosa [28], demonstrating that there is still room for improvement in this area.

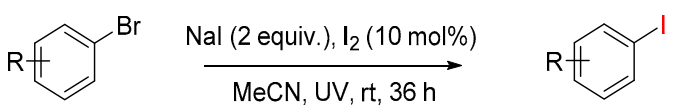

Scheme 2. Photo-induced aromatic halogen exchange reaction [27].

Our ongoing efforts in the development of synthetic methodologies and their applications in the synthesis of natural products and the active pharmaceutical ingredients prompted us to explore the possibilities of using microwave technology to promote protodecarboxylation reaction and decarboxylative iodination reaction, taking advantage of the efficiency generally rendered by this approach [29-32]. Herein, we report the outcomes of this work, in which the silver-catalyzed protodecarboxylation occurred smoothly under microwave-assisted heating and the decarboxylative iodination reaction afforded aryl iodides in high yields and great regioselectivity (Scheme 3). 


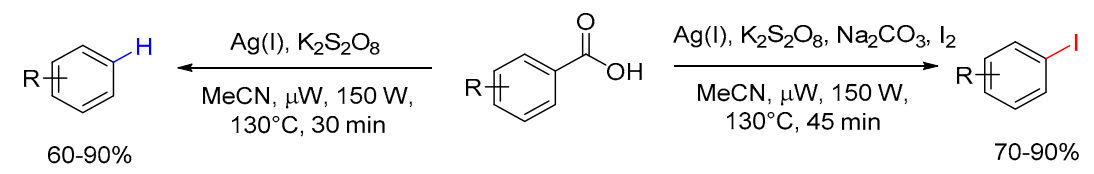

Scheme 3. Microwave-assisted silver-catalyzed protodecarboxylation and decarboxylative iodination of aromatic carboxylic acids (this work).

\section{Results and Discussion}

\subsection{Microwave-Assisted Protodecarboxylation Reaction of Aromatic Carboxylic Acids}

Our investigation started with ortho-bromo benzoic acid which has a moderate acid dissociation constant ( $\left.\mathrm{p} K_{\mathrm{a}} 2.88,25^{\circ} \mathrm{C}\right)$. Potassium peroxydisulfate, reported as an efficient oxidant by Greaney in their works [14], was employed as the oxidant. We were delighted to find that, under microwave irradiation ( $150 \mathrm{~W}, 2.45 \mathrm{GHz}$ magnetic frequency) at $130{ }^{\circ} \mathrm{C}$ with acetonitrile as solvent in the presence of $\mathrm{Ag}_{2} \mathrm{CO}_{3}(10 \mathrm{~mol} \%)$, the reaction completed in one hour to afford the expected protodecarboxylation product at a $64 \%$ yield. Encouraged by the initial results, we investigated the influence of the loading of silver catalyst and several different silver salts as candidate catalysts to optimize the reaction. Increasing the loading of silver catalyst from $10 \%$ to $40 \%$ did improve reaction yields to some extent (entries 1-5, Table 1). Of catalyst loading, 15\% was selected for further experimentation on the basis of its good efficiency and lower cost, when two equivalents of potassium peroxydisulfate was used. Although all the silver salts tested could promoted the protodecarboxylation effectively, $\mathrm{Ag}_{2} \mathrm{CO}_{3}$ gave the highest yield, followed by silver oxide, silver acetate, and silver triflate (entries 6-8). Potassium peroxydisulfate proved to be the oxidant of choice, when it was replaced by Oxone ${ }^{\circledR}$ (Sigma-Aldrich, St. Louis, MO, USA), the yield dropped to 30\% (entry 9). Further optimization showed that the solvent was important for the protodecarboxylation, acetonitrile, which is a polar solvent with adequate loss factor $(\tan \delta=0.062)$, provided the suitable substrate solubility and the energy absorbing efficiency, was the better solvent for the reaction, compared to DMF and DMSO. Also, the protodecarboxylation reaction occurred efficiently at $130{ }^{\circ} \mathrm{C}$ (entries 10-12), completed in one hour at the initial trials, but the reaction time could be further reduced to half hour after optimization of the other factors (entries 13 and 14).

Table 1. Selected results for the optimization of protodecarboxylation reaction conditions.<smiles>O=C(O)c1ccccc1Br</smiles>

$1 \mathrm{a}$

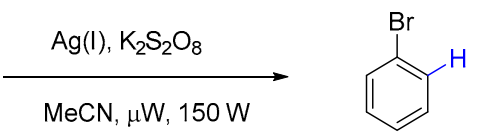

$2 a$

\begin{tabular}{|c|c|c|c|c|c|c|}
\hline Entry & Catalyst Loading (mol \%) & Ag(I) Catalyst (mol \%) & $\mathrm{K}_{2} \mathrm{~S}_{2} \mathrm{O}_{8}$ (equiv.) & Temperature $\left({ }^{\circ} \mathrm{C}\right)$ & Time (h) & Yield (\%) ${ }^{1}$ \\
\hline 1 & 10 & $\mathrm{Ag}_{2} \mathrm{CO}_{3}$ & 2 & 130 & 1 & 64 \\
\hline 2 & 15 & $\mathrm{Ag}_{2} \mathrm{CO}_{3}$ & 2 & 130 & 1 & 87 \\
\hline 3 & 20 & $\mathrm{Ag}_{2} \mathrm{CO}_{3}$ & 2 & 130 & 1 & 90 \\
\hline 4 & 30 & $\mathrm{Ag}_{2} \mathrm{CO}_{3}$ & 2 & 130 & 1 & 89 \\
\hline 5 & 40 & $\mathrm{Ag}_{2} \mathrm{CO}_{3}$ & 2 & 130 & 1 & 91 \\
\hline 6 & 15 & $\mathrm{Ag}_{2} \mathrm{O}$ & 2 & 130 & 1 & 68 \\
\hline 7 & 15 & AgOAc & 2 & 130 & 1 & 51 \\
\hline 8 & 15 & $\mathrm{AgSO}_{3} \mathrm{CF}_{3}$ & 2 & 130 & 1 & 43 \\
\hline 9 & 15 & $\mathrm{Ag}_{2} \mathrm{CO}_{3}$ & $2\left(\right.$ Oxone $\left.^{\circledR}\right)$ & 130 & 1 & 30 \\
\hline 10 & 15 & $\mathrm{Ag}_{2} \mathrm{CO}_{3}$ & 2 & 100 & 1 & 45 \\
\hline 11 & 15 & $\mathrm{Ag}_{2} \mathrm{CO}_{3}$ & 2 & 110 & 1 & 63 \\
\hline 12 & 15 & $\mathrm{Ag}_{2} \mathrm{CO}_{3}$ & 2 & 140 & 1 & 80 \\
\hline 13 & 15 & $\mathrm{Ag}_{2} \mathrm{CO}_{3}$ & 2 & 130 & 0.5 & 90 \\
\hline 14 & 15 & $\mathrm{Ag}_{2} \mathrm{CO}_{3}$ & 2 & 130 & 0.3 & 63 \\
\hline
\end{tabular}

1 Yields were determined by gas chromatography-mass spectrometry (GC-MS) analysis of the crude reaction mixture using chlorobenzene as an internal standard. 
With the optimized conditions in hand, the feasibility of this protocol was investigated. A variety of substituted aromatic carboxylic acids (Scheme 4) could proceed smoothly to afford the corresponding protodecarboxylation products. A relationship was revealed between the dissociation constants of carboxylic acids with the productivities of protodecarboxylation processes. Better yields were obtained for the carboxylic acids with relatively low $\mathrm{p} K_{\mathrm{a}}$ values, such as 2-bromo benzoic acid (2a), 2-nitro benzoic acid (2e), and 2-nitro-4, 5-dimethoxy benzoic acid (2k). In contrast, 4-bromo benzoic acid (2b), 4-nitro benzoic acid (2f), 3-bromo-4-fluoro benzoic acid (2i), and para- and meta-methoxy benzoic acid $(\mathbf{2 m}, \mathbf{2 n})$-which have higher acid dissociation constants-showed relatively poor yields. Interestingly, polycyclic carboxylic acid 1-naphthoic acid $\left(\mathbf{2 g}, \mathrm{p} K_{\mathrm{a}}\right.$ 3.6) showed more favorable yield than 2-naphthoic acid (2h, $\left.\mathrm{p} K_{\mathrm{a}} 4.17\right)$ and 5-bromonicotinic acid (2l, $\left.\mathrm{p} K_{\mathrm{a}} 4.02\right)$.

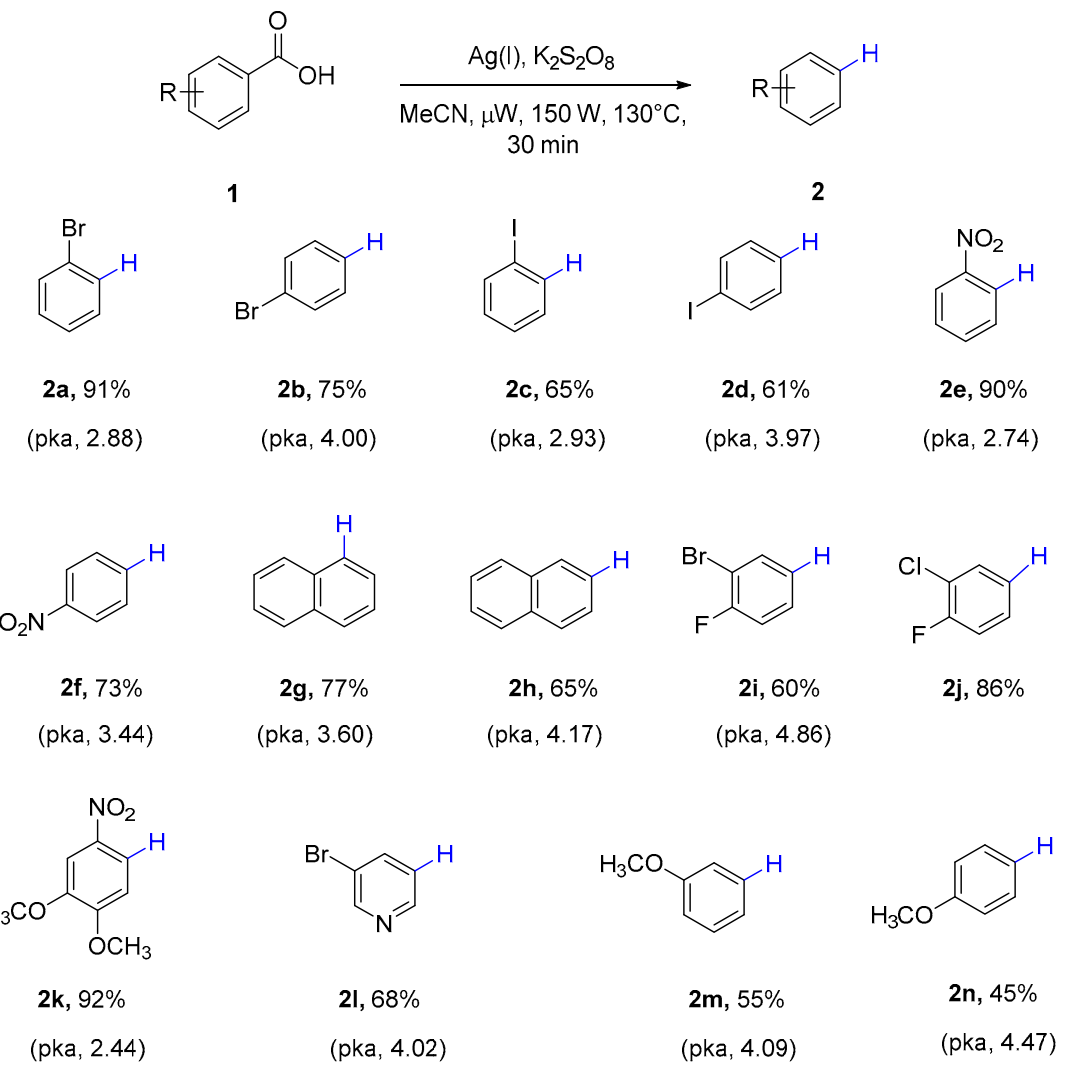

Scheme 4. Scope of microwave assisted protodecarboxylation of aromatic carboxylic acids. ${ }^{\text {a }}$ Reaction conditions: Aryl carboxylic acid $(0.50 \mathrm{mmol})$, silver(I) carbonate $(15 \mathrm{~mol} \%)$, potassium persulfate (2 equivalents) in $\mathrm{CH}_{3} \mathrm{CN}(4 \mathrm{~mL})$ was heated in microwave reactor at $130{ }^{\circ} \mathrm{C}$ for $30 \mathrm{~min}$. ${ }^{\mathrm{b}}$ Yields were determined by gas chromatography-mass spectrometry (GC-MS) analysis of the crude reaction mixture using chlorobenzene as an internal standard. Isolated yields for $\mathbf{2 c}, \mathbf{2 g}, \mathbf{2} \mathbf{i}, \mathbf{2 k}$. ${ }^{\mathrm{c}}$ pKa data $\left(25^{\circ} \mathrm{C}\right.$ in water), sources: U.S. National Library of Medicine and Reaxys.

The mechanism of oxidative decarboxylation with $\mathrm{Ag}(\mathrm{I})$ and $\mathrm{K}_{2} \mathrm{~S}_{2} \mathrm{O}_{8}$ has been investigated and proposed in the literature [12,14]. Potassium peroxydisulfate can oxidize the silver(I) salts to silver(II), which could covert carboxylate anion into aryl carboxylate radical. Microwaving facilitates and accelerates the elimination of carbon dioxide from carboxylate radical to generate the aryl radical, which can pick up a hydrogen from acetonitrile to form the product 2 (Scheme 5). Protodecarboxylation of 4,5-dimethoxy-2-nitrobenzoic acid in deuterated acetonitrile afforded the corresponding 1,2-dimethoxy-4-nitrobenzene-5- $d$ in the yield of $90 \%$ with D-content of $60 \%$, which properly vindicates the mechanism previously proposed. As this example showed, the deuterium exchange with free carboxylic acids in this process might provide an alternative 
route for the synthesis of deuterium-labeled compounds, useful for molecular structure analysis investigations of the reaction mechanism, and be employed as intermediates or metabolites for chemical biology research.

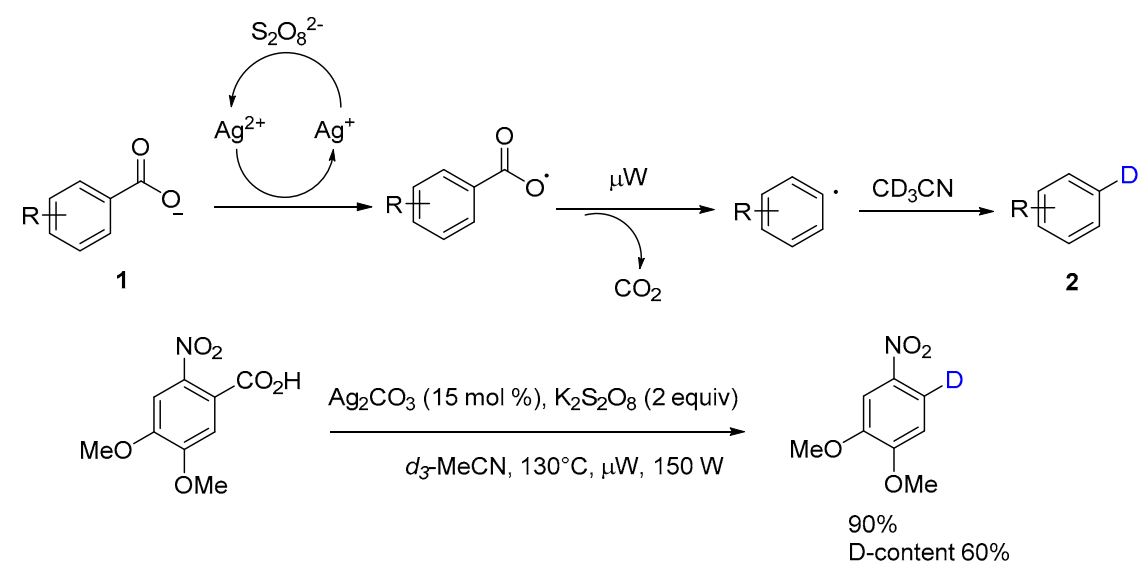

Scheme 5. Proposed mechanism of protodecarboxylation in $d_{3}$-acetonitrile.

\subsection{Microwave-Assisted Decarboxylative Iodination of Aromatic Carboxylic Acid}

With the optimized reaction condition established for protodecarboxylation, we were in a good position to investigate microwave-assisted decarboxylative iodination of aromatic carboxylic acid. We reckon that the aryl radical generated from decarboxylation of aromatic carboxylic acid will readily pick up iodine from a suitable source. Treatment of ortho-bromo benzoic acid with silver(I) carbonate (15 mol \%), potassium persulfate (2 equiv.) and iodine (2 equiv.) in acetonitrile under heating in microwave reactor $(150 \mathrm{~W})$ at $130{ }^{\circ} \mathrm{C}$ for $30 \mathrm{~min}$ afforded the corresponding 1-iodo-2-bromobenzene in the yield of $76 \%$ (Table 2, entry 1), no obvious formation of protodecarboxylation product had been observed. It clearly showed that the decarboxylative iodination was a faster reaction in the competition during the process. Additionally, an improved yield was observed when the loading of silver catalyst was increased from $15 \%$ to $30 \%$ (entries 2-4). Meanwhile, sodium iodide and potassium iodide were examined as the iodine source, although the reactions employing iodine generally gave good yields, no reaction occurred when $\mathrm{NaI}$ or KI was used (entries 5 and 6). Further optimization showed that the addition of sodium carbonate (2.0 equiv.) promoted the progress of the reaction (entry 7 ), supposedly facilitating the formation of carboxylate anion for decarboxylation and removal of hydrogen iodide from iodination reaction. The optimal temperature was $130^{\circ} \mathrm{C}$, the reaction yield deceased when the temperature was further raised (entries 8 and 9). Also this iodination required slightly longer time (45 $\mathrm{min}$ ) to complete (entries 10 and 11), compared to half an hour for protodecarboxylation reaction.

Table 2. Selected results for the optimization of decarboxylative iodination conditions.

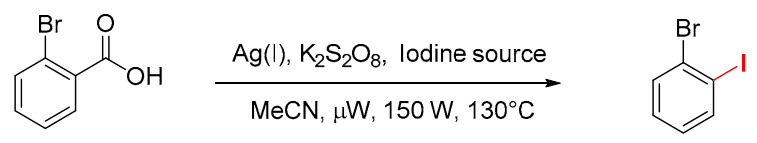

$1 \mathrm{a}$

$3 a$

\begin{tabular}{cccccc}
\hline Entry & Loading of $\mathbf{A g}_{\mathbf{2}} \mathbf{C O}_{\mathbf{3}} \mathbf{( \mathbf { m o l } \% )}$ & Iodine Source (equiv.) & Temperature $\left({ }^{\circ} \mathbf{C}\right)$ & Time $(\mathbf{h})$ & Yield (\%) ${ }^{\mathbf{1}}$ \\
\hline 1 & 15 & $\mathrm{I}_{2}(2)$ & 130 & 0.5 & 76 \\
2 & 20 & $\mathrm{I}_{2}(2)$ & 130 & 0.5 & 80 \\
3 & 25 & $\mathrm{I}_{2}(2)$ & 130 & 0.5 & 86 \\
4 & 30 & $\mathrm{I}_{2}(2)$ & 130 & 0.5 & 88 \\
5 & 25 & $\mathrm{KI}(2)$ & 130 & 0.5 & trace \\
6 & 25 & $\mathrm{NaI}(2)$ & 130 & 0.5 & trace \\
$7^{2}$ & 25 & $\mathrm{I}_{2}(2)$ & 130 & 0.5 & 93 \\
$8^{2}$ & 25 & $\mathrm{I}_{2}(2)$ & 140 & 0.5 & 80
\end{tabular}


Table 2. Cont.

\begin{tabular}{cccccc}
\hline Entry & Loading of $\left.\mathbf{A g}_{\mathbf{2}} \mathbf{C O}_{\mathbf{3}} \mathbf{( m o l} \%\right)$ & Iodine Source (equiv.) & Temperature $\left({ }^{\circ} \mathbf{C}\right)$ & Time (h) & Yield (\%) ${ }^{\mathbf{1}}$ \\
\hline $9^{2}$ & 25 & $\mathrm{I}_{2}(2)$ & 150 & 0.5 & 75 \\
$10^{2}$ & 25 & $\mathrm{I}_{2}(2)$ & 130 & 0.75 & 97 \\
$11^{2}$ & 25 & $\mathrm{I}_{2}(2)$ & 130 & 1 & 91 \\
\hline
\end{tabular}

${ }^{1}$ Yields were determined by gas chromatography-mass spectrometry (GC-MS) analysis of the crude reaction mixture using chlorobenzene as an internal standard. ${ }^{2}$ Sodium carbonate (2.0 equiv.) was added.

To explore the scope of this transformation, we investigated the decarboxylative iodination reaction of various aryl and heteroaryl carboxylic acids under the optimized reaction condition. In general, the procedure typically delivered the clean, corresponding aryl or heteroaryl iodides in the yield ranging from $56 \%$ to $99 \%$ (Scheme 6). The ortho-substituted aryl carboxylic acids generally gave very good yields, comparable to the protodecarboxylation abovementioned. Polysubstituted benzoic acids, such as 3-bromo-4-fluorobenzoic acid (3i) and 4, 5-dimethoxy-2-nitrobenzoic acid (3k) smoothly underwent the reaction to produce aryl iodides in good yields.

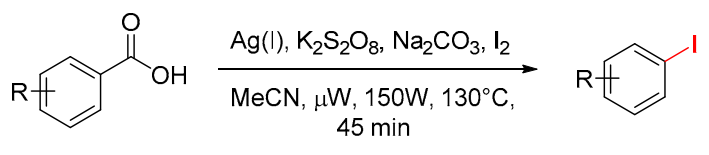

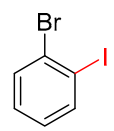

$3 a, 97 \%$<smiles>O=[N+]([O-])c1ccc(I)cc1</smiles><smiles>COc1cc(I)c([N+](=O)[O-])cc1OC</smiles>

$3 \mathrm{k}, 85 \%$

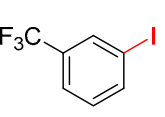

3o, $92 \%$<smiles>Brc1ccc(I)cc1</smiles>

$3 b, 72 \%$<smiles>Ic1cccc2ccccc12</smiles>

$3 g, 73 \%$<smiles>Brc1cncc(I)c1</smiles>

$31,63 \%$<smiles>Ic1ccccc1I</smiles>

$3 c, 99 \%$<smiles>Ic1ccc(I)cc1</smiles>

$3 d, 75 \%$<smiles>O=[N+]([O-])c1ccccc1I</smiles>

$3 e, 92 \%$<smiles>Ic1ccc2ccccc2c1</smiles>

$3 \mathrm{~h}, 56 \%$<smiles>Fc1ccc(I)cc1Br</smiles>

$3 i, 80 \%$<smiles>COc1cc(I)cc(I)c1I</smiles>
( a mixture of di-, triiodio products) $3 \mathrm{~m}, 97 \%$ (combined yield)<smiles>Fc1ccccc1I</smiles>

$3 q, 90 \%$<smiles>Fc1ccc(I)cc1Cl</smiles>

3j, $83 \%$<smiles>COc1ccc(I)cc1I</smiles>

3n, $86 \%$<smiles>Fc1ccc(I)cc1</smiles>

$3 r, 65 \%$

Scheme 6. Scope of microwave assisted decarboxylative iodination of aromatic carboxylic acids.

a Reaction conditions: Aryl carboxylic acid $(0.50 \mathrm{mmol})$, silver(I) carbonate $(25 \mathrm{~mol} \%)$, sodium carbonate (2.0 equiv.), potassium persulfate (2 equiv.), and iodine (2 equiv.) in $\mathrm{CH}_{3} \mathrm{CN}(4 \mathrm{~mL}$ ) was heated in microwave reactor at $130{ }^{\circ} \mathrm{C}$ for $45 \mathrm{~min}$. ${ }^{\mathrm{b}}$ Isolated yields.

In terms of nitro-substituted benzoic acids (3e, $\mathbf{3 f}$ ) and monofluorine-substituted benzoic acids $(\mathbf{3 q}, \mathbf{3 r})$, ortho-substituted acids showed better yields than their para-substituted isomers. Iodination occurred smoothly on trifluoromethyl-substituted benzoic acids as well with satisfactory yields $(\mathbf{3 0}, \mathbf{3 p})$. Diverse results were obtained for 1 and 2-substituted naphthoic acids $(3 \mathbf{g}, 3 \mathbf{h})$ and heterocyclic 
carboxylic acids, such as 5-Bromonicotinic acid (31). Interestingly, aryl carboxylic acids with strong electron-donating methoxy group, produced a mixture of diiodo- and triiodo-substituted products for 3-methoxybenzoic acid (3m) and a single disubstituted product for 4-methoxybenzoic acid (3n). Although the exact rational for the formation of these compounds is not clear, it was tentatively suggested that the presence of electron-donating group activates the aromatic ring for a direct electrophilic iodination under the adopted reaction condition.

We also explored the probabilities of use this methodology for decarboxylative bromination and chlorination reaction, using $\mathrm{Br}_{2}$, NBS (N-bromosuccinimide) as a bromine source, and NCS ( $\mathrm{N}$-chlorosuccinimide) as a chlorine source. These reactions occurred to give the corresponding bromine and chlorine substituted aromatic compounds but with poor yields of $20-40 \%$. Transformation of carboxylic acid group into trifluoromethyl functional group attracts great interests from drug discovery and industry. Our work to trap trifluoromethyl group with various trifluoromethyl reagents, such as $\mathrm{CF}_{3} \mathrm{I}, \mathrm{TMSCF}_{3}$, Umemoto reagent, Togni reagent, and radical reagents $\left(\mathrm{Na}_{2} \mathrm{SO}_{3} \mathrm{CF}_{3}\right.$, trifluoroacetic acid) is still ongoing, and will be reported in due course.

\section{Experimental Details}

\subsection{General Procedure for Microwave-Assisted Protodecarboxylation Reaction of Aromatic Carboxylic Acid}

An oven-dried microwave reaction vial $(35 \mathrm{~mL})$ was charged with benzoic acid $(0.50 \mathrm{mmol})$, silver(I) carbonate ( $15 \mathrm{~mol} \%$ ), potassium persulfate (2 equiv.) in $4 \mathrm{~mL}$ acetonitrile. The mixture was heated in microwave reactor (CEM Discover-SP, Buckingham, UK) at $130{ }^{\circ} \mathrm{C}$ for $30 \mathrm{~min}$, then allowed to cool down. For the measurement of volatile products, chlorobenzene $(0.50 \mathrm{mmol})$ was added into the reaction mixture, and analysis was carried out on GC-MS (Agilent 5975C Triple Axis GC-MS, Santa Clara, CA, USA). Otherwise, the reaction mixture was diluted with $\mathrm{Et}_{2} \mathrm{O}(10 \mathrm{~mL})$ and washed with saturated aqueous $\mathrm{NaHCO}_{3}(10 \mathrm{~mL})$. The aqueous layer was extracted with $\mathrm{Et}_{2} \mathrm{O}(2 \times 10 \mathrm{~mL})$ and the combined organic layers were dried with anhydrous $\mathrm{MgSO}_{4}$, then filtered and concentrated under reduced pressure. The crude product was purified by the short silica column and eluted with n-hexane to give the product.

\subsection{General Procedure for Microwave-Assisted Decarboxylative Iodination Reaction of Aromatic Carboxylic Acid}

An oven-dried microwave reaction vial $(35 \mathrm{~mL})$ was charged with 2-nitro benzoic acid $(0.50 \mathrm{mmol})$, silver(I) carbonate ( $25 \mathrm{~mol} \%$ ), potassium persulfate (2 equiv.), sodium carbonate ( 2.0 equiv.), and iodine ( 2 equiv.) in $4 \mathrm{~mL}$ acetonitrile. The mixture was heated in microwave reactor at $130{ }^{\circ} \mathrm{C}$ for $45 \mathrm{~min}$, then allowed to cool down, diluted with EtOAc $(10 \mathrm{~mL})$, and washed with saturated aqueous $\mathrm{Na}_{2} \mathrm{~S}_{2} \mathrm{O}_{3}(10 \mathrm{~mL})$. The resulting mixture was extracted with EtOAc $(2 \times 10 \mathrm{~mL})$ and the combined organic layers were dried with anhydrous $\mathrm{MgSO}_{4}$, filtered, and concentrated under reduced pressure. The crude product was purified by the short silica column and eluted with n-hexane (see Supplementary Materials).

\section{Conclusions}

In summary, we have demonstrated that microwave-assisted protodecarboxylation and decarboxylative iodination could proceed smoothly on aromatic and heterocyclic carboxylic acids to produce the corresponding aromatic compounds and regioselective aromatic iodide. Significantly, employing microwave technology greatly facilitates the process, the reactions could be completed in less than one hour. This work provides a practical and general protocol for the synthesis of deuterated and iodine-labelling intermediate or compounds, which could be used for the radio medicine and biological research.

Supplementary Materials: The following are available online at www.mdpi.com/2073-4344/7/11/314/s1, Experimental procedure and spectral data for the iodides. 
Acknowledgments: The authors thank the Jiangsu Science and Technology Program (Basic Research Program) (Grant No. BK20131180) for the funding.

Author Contributions: Y.L. conceived and designed the experiments; K.Z. performed the experiments and analyzed the data; Y.L. wrote the paper.

Conflicts of Interest: The authors declare no conflict of interest.

\section{References}

1. Goossen, L.J.; Rodriguez, N.; Goossen, K. Carboxylic acids as substrates in homogeneous catalysis. Angew. Chem. Int. Ed. Engl. 2008, 47, 3100-3120. [CrossRef] [PubMed]

2. Goossen, L.J.; Goossen, K.; Rodriguez, N.; Blanchot, M.; Linder, C.; Zimmermann, B. New catalytic transformations of carboxylic acids. Pure Appl. Chem. 2008, 80, 1725-1733. [CrossRef]

3. Font, M.; Quibell, J.M.; Perry, G.J.P.; Larrosa, I. The use of carboxylic acids as traceless directing groups for regioselective C-H bond functionalisation. Chem. Commun. 2017, 53, 5584-5597. [CrossRef] [PubMed]

4. Rodriguez, N.; Goossen, L.J. Decarboxylative coupling reactions: A modern strategy for C-C-bond formation. Chem. Soc. Rev. 2011, 40, 5030-5048. [CrossRef] [PubMed]

5. Yi, H.; Zhang, G.; Wang, H.; Huang, Z.; Wang, J.; Singh, A.K.; Lei, A. Recent advances in radical C-H activation/radical cross-coupling. Chem. Rev. 2017, 117, 9016-9085. [CrossRef] [PubMed]

6. Carrillo-Arcos, U.A.; Rojas-Ocampo, J.; Porcel, S. Oxidative cyclization of alkenoic acids promoted by AgOAc. Dalton Trans. 2016, 45, 479-483. [CrossRef] [PubMed]

7. Jafarpour, F.; Zarei, S.; Olia, M.B.; Jalalimanesh, N.; Rahiminejadan, S. Palladium-catalyzed decarboxylative cross-coupling reactions: A route for regioselective functionalization of coumarins. J. Org. Chem. 2013, 78, 2957-2964. [CrossRef] [PubMed]

8. Arroniz, C.; Ironmonger, A.; Rassias, G.; Larrosa, I. Direct ortho-arylation of ortho-substituted benzoic acids: Overriding Pd-catalyzed protodecarboxylation. Org. Lett. 2013, 15, 910-913. [CrossRef] [PubMed]

9. Bhadra, S.; Dzik, W.I.; Goossen, L.J. Synthesis of aryl ethers from benzoates through carboxylate-directed C-H-activating alkoxylation with concomitant protodecarboxylation. Angew. Chem. Int. Ed. Engl. 2013, 52, 2959-2962. [CrossRef] [PubMed]

10. Dupuy, S.; Nolan, S.P. Gold(I)-catalyzed protodecarboxylation of (hetero)aromatic carboxylic acids. Chemistry 2013, 19, 14034-14038. [CrossRef] [PubMed]

11. Goossen, L.J.; Thiel, W.R.; Rodriguez, N.; Linder, C.; Melzer, B. Copper-catalyzed protodecarboxylation of aromatic carboxylic acids. Adv. Synth. Catal. 2007, 349, 2241-2246. [CrossRef]

12. Cornella, J.; Sanchez, C.; Banawa, D.; Larrosa, I. Silver-catalysed protodecarboxylation of ortho-substituted benzoic acids. Chem. Commun. 2009, 7176-7178. [CrossRef] [PubMed]

13. Grainger, R.; Cornella, J.; Blakemore, D.C.; Larrosa, I.; Campanera, J.M. The ortho-substituent effect on the Ag-catalysed decarboxylation of benzoic acids. Chemistry 2014, 20, 16680-16687. [CrossRef] [PubMed]

14. Seo, S.; Taylor, J.B.; Greaney, M.F. Protodecarboxylation of benzoic acids under radical conditions. Chem. Commun. 2012, 48, 8270-8272. [CrossRef] [PubMed]

15. Ma, D.; Cai, Q. Copper/amino acid catalyzed cross-couplings of aryl and vinyl halides with nucleophiles. Acc. Chem. Res. 2008, 41, 1450-1460. [CrossRef] [PubMed]

16. Evano, G.; Blanchard, N.; Toumi, M. Copper-mediated coupling reactions and their applications in natural products and designed biomolecules synthesis. Chem. Rev. 2008, 108, 3054-3131. [CrossRef] [PubMed]

17. Barluenga, J.; Gonzalez, J.M.; Garciamartin, M.A.; Campos, P.J.; Asensio, G. Acid-mediated reaction of bis(pyridine)iodonium(I) tetrafluoroborate with aromatic-compounds-A selective and general iodination method. J. Org. Chem. 1993, 58, 2058-2060. [CrossRef]

18. Bunevicius, R.; Kazanavicius, G.; Zalinkevicius, R.; Prange, A.J., Jr. Effects of thyroxine as compared with thyroxine plus triiodothyronine in patients with hypothyroidism. N. Engl. J. Med. 1999, 340, 424-429. [CrossRef] [PubMed]

19. Hallouard, F.; Anton, N.; Choquet, P.; Constantinesco, A.; Vandamme, T. Iodinated blood pool contrast media for preclinical X-ray imaging applications-A review. Biomaterials 2010, 31, 6249-6268. [CrossRef] [PubMed]

20. Pimlott, S.L.; Sutherland, A. Molecular tracers for the PET and spect imaging of disease. Chem. Soc. Rev. 2011, 40, 149-162. [CrossRef] [PubMed] 
21. Seevers, R.H.; Counsell, R.E. Radioiodination techniques for small organic-molecules. Chem. Rev. 1982, 82, 575-590. [CrossRef]

22. Baird, W.C.; Surridge, J.H. Halogenation with copper(II) halides-Synthesis of aryl iodides. J. Org. Chem. 1970, 35, 3436-3442. [CrossRef]

23. Naumann, D.; Ruther, G. Synthesis of aryl iodine(III) difluorides by direct fluorination of aryl iodides. J. Fluorine Chem. 1980, 15, 213-222. [CrossRef]

24. Cant, A.A.; Bhalla, R.; Pimlott, S.L.; Sutherland, A. Nickel-catalysed aromatic Finkelstein reaction of aryl and heteroaryl bromides. Chem. Commun. 2012, 48, 3993-3995. [CrossRef] [PubMed]

25. Chen, M.; Ichikawa, S.; Buchwald, S.L. Rapid and efficient copper-catalyzed Finkelstein reaction of (hetero)aromatics under continuous-flow conditions. Angew. Chem. Int. Ed. Engl. 2015, 54, 263-266. [CrossRef] [PubMed]

26. Klapars, A.; Buchwald, S.L. Copper-catalyzed halogen exchange in aryl halides: An aromatic Finkelstein reaction. J. Am. Chem. Soc. 2002, 124, 14844-14845. [CrossRef] [PubMed]

27. Li, L.; Liu, W.; Zeng, H.; Mu, X.; Cosa, G.; Mi, Z.; Li, C.J. Photo-induced metal-catalyst-free aromatic Finkelstein reaction. J. Am. Chem. Soc. 2015, 137, 8328-8331. [CrossRef] [PubMed]

28. Perry, G.J.P.; Quibell, J.M.; Panigrahi, A.; Larrosa, I. Transition-metal-free decarboxylative iodination: New routes for decarboxylative oxidative cross-couplings. J. Am. Chem. Soc. 2017, 139, 11527-11536. [CrossRef] [PubMed]

29. Mavandadi, F.; Pilotti, A. The impact of microwave-assisted organic synthesis in drug discovery. Drug Discov. Today 2006, 11, 165-174. [CrossRef]

30. Lidstrom, P.; Westman, J.; Lewis, A. Enhancement of combinatorial chemistry by microwave-assisted organic synthesis. Comb. Chem. High Throughput Screen. 2002, 5, 441-458. [CrossRef] [PubMed]

31. Goossen, L.J.; Manjolinho, F.; Khan, B.A.; Rodriguez, N. Microwave-assisted Cu-catalyzed protodecarboxylation of aromatic carboxylic acids. J. Org. Chem. 2009, 74, 2620-2623. [CrossRef] [PubMed]

32. Ferro, S.; Grazia, S.D.; De Luca, L.; Gitto, R.; Faliti, C.E.; Debyzer, Z.; Chimirri, A. Microwave assisted organic synthesis (MAOS) of small molecules as potential HIV-1 integrase inhibitors. Molecules 2011, 16, 6858-6870. [CrossRef] [PubMed] 